

\title{
A novel electrochemical method for olive oil acidity determination
}

Marco Grossi, Giuseppe Di Lecce, Tullia Gallina Toschi, Bruno Riccò

\section{To cite this version:}

Marco Grossi, Giuseppe Di Lecce, Tullia Gallina Toschi, Bruno Riccò. A novel electrochemical method for olive oil acidity determination. Microelectronics Journal, 2014, 45 (12), pp.1701-1707. 10.1016/j.mejo.2014.07.006 . hal-01276343

\section{HAL Id: hal-01276343 \\ https://hal.science/hal-01276343}

Submitted on 25 Feb 2016

HAL is a multi-disciplinary open access archive for the deposit and dissemination of scientific research documents, whether they are published or not. The documents may come from teaching and research institutions in France or abroad, or from public or private research centers.
L'archive ouverte pluridisciplinaire HAL, est destinée au dépôt et à la diffusion de documents scientifiques de niveau recherche, publiés ou non, émanant des établissements d'enseignement et de recherche français ou étrangers, des laboratoires publics ou privés. 


\title{
A Novel Electrochemical Method for Olive Oil Acidity Determination
}

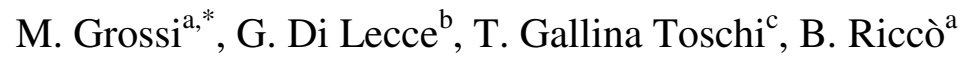

* Corresponding author : marco.grossi8@ unibo.it , Tel. 0039-0512093082, Fax 0039-0512093785

a Department of Electrical, Electronic and Information Engineering “Guglielmo Marconi” (DEI), University of Bologna, Bologna, Italy

b Department of Food Chemistry, Eurofins Chemical Control, Cuneo, Italy

c Department of Agricultural and Food Sciences - DISTAL, University of Bologna, Cesena, Italy

\begin{abstract}
Olive oil is a very important product due to its nutritional value, sensory and antioxidant properties. National and international regulations define basic quality parameters (such as acidity and peroxide index) to discriminate high quality oils (extra virgin olive oil) from those of lower quality.

The standard procedures to measure acidity and peroxide index feature manual titration requiring laboratory environment and trained personnel.

In this paper a novel technique, based on electrical impedance spectroscopy, is presented and implemented as a low-cost, mobile instrument to be used everywhere and by anybody, with substantial improvements of the current quality control of olive oil producers of any dimension.

The presented method is validated on 39 olive oil samples with different levels of acidity, peroxide index and total phenolic content.

The results show that the conductance of an emulsion of olive oil with a hydro-alcoholic solution is correlated with the oil acidity. Furthermore, since, for the same oil, the emulsion conductance varies with the oil storage conditions (because of increases in the peroxide index), the presented technique could also be used to evaluate product ageing.
\end{abstract}

Keywords: olive oil; free acidity; quality test; impedance technique; embedded sensor system. 


\section{Introduction}

In the Mediterranean diet, olive oil is a major source of mono-unsaturated fatty acids, and is highly appreciated as for numerous benefic biological effects [1].

Currently, about $95 \%$ of the world olive oil production is due to countries in the Mediterranean area, with Italy being the second largest olive oil producer after Spain [2].

Olive oil quality is affected by different factors, such as: seasonal weather, the olives ripening stage, extraction process and last but not the least the storage conditions (light and temperature) [3].

The most important parameters that define the olive oil quality are acidity and peroxide index. The former, defined as the amount of fatty acids no longer linked to their parent triglyceride molecules, is measured as percent of oleic acid in 100 grams of oil. The latter, instead, is an indicator of the oil primary oxidation and is expressed as milliequivalent of active oxygen per kilogram of oil (meq $\mathrm{O}_{2} / \mathrm{kg}$ oil). If storage conditions are not adequate (essentially due to lack of protection against heat and light), oil oxidation takes place and degrades the product quality.

The European Commission Regulation No. 2568/91 and subsequent amendments impose a maximum acidity of $0.8 \mathrm{~g}$ oleic acid $/ 100 \mathrm{~g}$ oil and a maximum peroxide index of $20 \mathrm{meq} \mathrm{O}_{2} / \mathrm{kg}$ oil, for extra-virgin olive oil [4].

The standard techniques to measure acidity and peroxide index in olive oil are titrations that can be carried out only by skilled personnel in a laboratory environment. However, since cheap, fast and in-situ determination of quality parameters would be useful during oil production, innovative procedures are currently investigated and several techniques have been proposed.

One of the most promising approach to the problem is based on Near-Infrared (NIR) spectroscopy, allowing to estimate acidity and peroxide index by optical spectroscopy analysis of the transmission spectra in the wavenumber range 4541 to $11726 \mathrm{~cm}^{-1}$ [5]. NIR technique has also been used to detect adulteration of extra-virgin olive oil with lower quality products [6]. Furthermore, a recently proposed method, called spectral nephelometry, combining absorption spectroscopy and 
nephelometry, has been used to obtain oil "fingerprints" allowing to distinguish products of different geographical origins [7].

All the techniques based on light interaction with the sample are very promising since they allow fast, non destructive measurements with minimal preparation of the sample. However, the instrumentation needed is expensive and the procedures must be separately calibrated for different types of oil (produced from olives of different varieties, different geographical origin, etc).

A different approach, microwave dielectric spectroscopy [8][9], is based on dielectric measurements allowing fast discrimination of different acidity levels. However, to achieve good accuracy test signals of high frequencies (hundreds of $\mathrm{MHz}$ ) are necessary, and these, in turn, require expensive instrumentation (time domain reflectometry).

A pH-metric technique for acidity determination (by extraction of free fatty acids into a solvent phase) has also been proposed that does not require titration [10]. While such a technique provides fast response (within a minute), the $\mathrm{pH}$ - meter with an aqueous reference electrode is expensive and the reagents $(0.20 \mathrm{M}$ triethanolamine in a 1:1 solution of water and isopropanol) must be properly disposed of after use.

In such a context, this paper presents a novel technique to measure olive oil acidity, based on Electrical Impedance Spectroscopy (EIS), that is suitable for the realization of a simple, low-cost, mobile instrument to be used everywhere and by anybody, with substantial improvements in the current situation of oil producers of any dimension.

With EIS the sample under test (SUT) is stimulated with a sinusoidal test signal in a broad range of frequencies and its electrical response $(\mathrm{IZI}$ and $\operatorname{Arg}(\mathrm{Z}))$ is measured [11]. In recent years, this technique has been used for the characterization of different characteristics of various products, such as, in particular: water and lipid content in meat [12], dilution factor in apple puree [13], ripening stage of different types of fruits [14][15], bacterial concentration in ice-cream [16][17], raw milk [18], beer [19] and water [20]. 
In in this work, EIS features a SUT consisting of an emulsion of olive oil with a hydro-alcoholic (i.e. aqueous) solution, tested with signal frequencies ranging from $20 \mathrm{~Hz}$ to $2 \mathrm{MHz}$. The results show that the method is capable of discriminating olive oils of different acidity levels and peroxide indexes, in particular in order to distinguish extra virgin olive oil from products of lower quality. Moreover, a portable instrument (i.e. an embedded sensor system) based on such a technique has been realized that allows in-situ acidity measurements with a short time response (40 seconds), thus opening the road to distributed control procedures, affordable also by small oil producers, with obvious benefits in terms of product quality.

\section{Materials and Methods}

A set of 39 olive oil samples (taken from local markets as well as coming from Italian mills) have been tested to investigate the correlation between their quality parameters (acidity and peroxide index) and the electrical conductivity of emulsions of such products with a suitable solution of safe and easily disposable components.

\subsection{Electrochemical sensor}

Virgin olive oil contains a limited amount (1-2\%) of chemicals known as "minor polar components" (normally indicated as CMP and including free fatty acids, monoacylglycerols, diacylglycerols, aliphatic alcohols di-and triterpene, sterols and hydrophilic antioxidants [21]), that are soluble in a hydrophilic solution. For this reason, an emulsion of olive oil with a hydro-alcoholic solution made of ethanol $(60 \%)$ and distilled water $(40 \%)$ has been used in the experiments made. Ethanol has been chosen to adjust the polarity of the solution and preferred to methanol because it is not toxic.

The "measurement head" of the sensor hosting the emulsion is a $50 \mathrm{ml}$ tube modified to include a couple of cap-shaped stainless steel electrodes $(6 \mathrm{~mm}$ in diameter, spaced by $12 \mathrm{~mm}$ one from the other) required for the electrical characterization. Different ratios oil/aqueous solution have been tested and the results are reported in Section III. The oil sample and the solution are mixed and 
stirred to create the emulsion. The electrical measurements are performed with the sensor in a thermal incubator at $20^{\circ} \mathrm{C}$.

\subsection{Measurement setup}

The measurement set-up of Fig. 1 a, making use of benchtop instruments is used to: a) validate the characterization procedure introduced in this work; b) determine the essential features of the lowcost, portable, embedded system representing the final goal of this work.

The thermal incubator Binder APT KB 53 is set to $20{ }^{\circ} \mathrm{C}$ to guarantee that all samples are tested at the same temperature. The Agilent E4980A LCR meter, controlled by a laptop through a USB interface, applies to the sensor electrodes a sinusoidal voltage of $100 \mathrm{mV}$ and measures the sample electrical parameters $\mid \mathrm{ZI}$ and $\operatorname{Arg}(\mathrm{Z})$ over the frequency range $20 \mathrm{~Hz}-2 \mathrm{MHz}$. The laptop acquires the data from the LCR meter and stores them on the hard disk. All the programs for instrumentation control have been developed with LabVIEW (National Instruments, USA).

\subsection{Equivalent circuit model}

Both the hydro-alcoholic solution and the emulsion have been characterized with the measurement set-up presented in the previous Subsection. A typical Nyquist diagram, i.e. $\operatorname{Im}(Z)$ vs $\operatorname{Re}(Z)$ for the entire frequency range, is shown in Fig. 1 (b). As can be seen, in both cases the plot is a semi-circle with the center on the $x$-axis, while $\operatorname{Re}(Z)$ as well as $\operatorname{Im}(Z)$ tend to 0 as $\omega \rightarrow+\infty$, indicating that the sensor-sample system is well described by an equivalent circuit formed by a conductance in parallel with a capacitance. Thus:

$$
\begin{aligned}
& Y=1 / Z=G_{m}+j \omega C_{m}, \\
& Z=\frac{G_{m}-j \omega C_{m}}{G_{m}{ }^{2}+\left(\omega C_{m}\right)^{2}},
\end{aligned}
$$

where $G_{m}$ and $C_{m}$ account for the sample conductivity and dielectric properties, respectively. 
The electrical parameters have been calculated by fitting the equivalent circuit formed by a conductance $G_{m}$ in parallel with a capacitance $C_{m}$ using Multiple Electrochemical Impedance Spectra Parametrization (MEISP) v3.0 by Kumho Chemical Laboratories. The hydro-alcoholic solution is characterized by values of $\mathrm{G}_{\mathrm{m}} 0.711 \pm 0.038 \mu \mathrm{S}$ and $\mathrm{C}_{\mathrm{m}} 7.396 \pm 0.188 \mathrm{pF}$.

As such a solution is mixed with the oil and the emulsion is created, $\mathrm{G}_{\mathrm{m}}$ exhibits a strong increase while $C_{m}$ decreases. The increase of $G_{m}$ is essentially due to the dissociation of the free fatty molecule $\mathrm{RCOOH}$ (where R is the monovalent functional group $\mathrm{CH}_{3}\left(\mathrm{CH}_{2}\right)_{7} \mathrm{CH}=\mathrm{CH}\left(\mathrm{CH}_{2}\right)_{7}$ ) as well as of other polar compounds present in the oil.

Measurements on all available olive oil samples have shown that $\mathrm{C}_{\mathrm{m}}$ is almost always the same, as expected since the dielectric properties of vegetable oils at low frequencies $(<10 \mathrm{MHz})$ are known not to vary significantly from one case to the other.

On the contrary, $G_{m}$ varies significantly with different oil samples and turns out to be well suited for acidity determination.

The data obtained with measurements using the full spectrum range $20 \mathrm{~Hz}-2 \mathrm{MHz}$ have shown that, as expected from equation (1), $\operatorname{Re}(\mathrm{Y})$ is (almost) constant throughout this whole frequency range. Fig. 1 (c) shows plots of $|\mathrm{Y}|$ and $\operatorname{Re}(\mathrm{Y})$ vs frequency for emulsions with oils featuring different values of acidity. As can be seen, IYI is almost constant (at a value that correlates with the sample acidity) for frequencies lower than $10 \mathrm{kHz}$, while for $\mathrm{f}>200 \mathrm{kHz}$ it has (approximately) the same value for all the samples.

In practice, $|\mathrm{Y}|$ is dominated by the emulsion conductance $\mathrm{G}_{\mathrm{m}}$ at low frequencies, while the emulsion capacitance $\mathrm{C}_{\mathrm{m}}$ dominates at high frequencies. As for $\operatorname{Re}(\mathrm{Y})$ the measured value is almost constant on the whole spectrum with very stable values for frequencies lower than $100 \mathrm{kHz}$.

Thus $\mathrm{G}_{\mathrm{m}}$ can be calculated from data taken at a single frequency with an error $<0.5 \%$ compared to the value obtained using the full frequency spectrum $20 \mathrm{~Hz}-2 \mathrm{MHz}$, and this largely simplifies the design of the embedded system presented in Section 4.

\subsection{Reference methods}


All tested samples have been analyzed using the reference methods (i.e. manual titration) defined by the European Commission Regulation No. 2568/91 [4].

In the case of acidity determination, the titrant is sodium hydroxide $\mathrm{NaOH} 0.1 \mathrm{M}$, while the titrand is a solution composed of an alcohol-diethyl ether mix, phenolphthalein (as indicator) and the oil sample.

Instead, for the determination of peroxide index, the titrant is sodium thiosulphate $\mathrm{Na}_{2} \mathrm{~S}_{2} \mathrm{O}_{3}$ and the titrand a mix of acetic acid, chloroform, saturated solution of potassium iodide KI, starch (as indicator) and the oil sample.

\section{Results and discussion}

First, measurement for acidity determination has been optimized finding the best oil to hydroalcoholic solution ratio. Successively, the effect of storage conditions has been considered. Finally, a set of 39 olive oils (purchased from markets as well as taken from Italian olive oil mills) have been used to validate the resulting techniques.

\subsection{Choice of the oil/hydro-alcoholic solution ratio}

Three different oil vs. hydro-alcoholic ratios have been investigated to achieve the best accuracy in acidity determination, namely: (a) $15 \mathrm{ml}$ oil and $15 \mathrm{ml}$ solution, (b) $5 \mathrm{ml}$ oil and $15 \mathrm{ml}$ solution, (c) $1 \mathrm{ml}$ oil and $15 \mathrm{ml}$ solution.

To this purpose, an olive oil sample has been artificially modified with the addition of different concentration of oleic acid to obtain samples differing only for their acidity, while presenting the same remaining composition (peroxide index, polyphenol content, fatty acid profile etc.). Four different test samples were created, featuring acidity of : $0.35 \%, 0.75 \%, 1.25 \%$ and $2.25 \%$. All measurements have been carried out in triplicate and both mean value and standard deviation have been calculated.

The measured values of $G_{m}$ plotted vs the sample acidity are shown in Fig. 2. As can be seen, in all cases $G_{m}$ increases with the sample acidity, while the best results are obtained with emulsions 
featuring $1 \mathrm{ml}$ of oil and $15 \mathrm{ml}$ of hydro-alcoholic solution (case c). In such a case, in fact, as also indicated in Table 1, the sensitivity (variation of $\mathrm{G}_{\mathrm{m}}$ in $\mu \mathrm{S}$ for $1 \%$ variation of the sample acidity) is almost two and six time larger than that of case (b) and case (a), respectively.

The same holds for the error in acidity estimation, with case (c) achieving a very low value $(0.0756 \%)$, more than 15 times lower than case (a).

As for linearity, the results of case (b) and (c) are comparable and much better than (a).

Thus, in our subsequent work only emulsions of $1 \mathrm{ml}$ of olive oil with $15 \mathrm{ml}$ of hydro-alcoholic solution have been used.

\subsection{Effects of the storage conditions}

To investigate if $\mathrm{G}_{\mathrm{m}}$ measurements can be used to investigate, and possibly monitor, the effects of olive oil storage conditions the following stress test has been performed. Three different extravirgin olive oil samples initially in good storage conditions (i.e. peroxide index between 7 and 10 meq $\mathrm{O}_{2} / \mathrm{kg}$ oil) have been irradiated with UV for different amount of time and the conductance of the emulsion described above has been measured before the exposition to UV as well as after 2.6, 4.8 and 7.6 days, respectively. As shown in Fig. 3, the results indicate a strong increase in $G_{m}$ (due to both primary and secondary oxidation products [21]) with the duration of the UV exposure. Linear regression lines have been determined for all the three samples and the calculated slope (i.e. $\mathrm{G}_{\mathrm{m}}$ variation for day of UV exposure) ranges from 0.326 to $0.392 \mu \mathrm{S} /$ day.

\subsection{Technique validation}

A set of 39 olive oils, substantially different from each other for olive cultivar, acidity, peroxide index and total phenolic content, have been used to validate the optimized technique described in the previous Sections. These products, characterized by means of the standard procedures [4], feature acidity values from $0.1 \%$ to $2.25 \%$, peroxide index from 4 to 75 meq $\mathrm{O}_{2} / \mathrm{kg}$ oil and phenolic content from 30 to $700 \mathrm{ppm}$.

Fig. 4 (a) clearly shows that $G_{m}$ increases with oil acidity value for samples in good storage conditions (i.e. peroxide index <20). The measured conductance is linearly related to oil acidity for 
values $<$ than $1 \%$, while for higher values the sensitivity tends to decrease. In particular, the calculated linear regression line equation for acidity $<1 \%$ is $G_{m}=3.15$ acidity +0.8 and the determination factor is $\mathrm{R}^{2}=0.74$. Thus, from the measured data, extra-vergin oils can be easily identified by setting a conductance threshold $\mathrm{G}_{\mathrm{m}}<2.75 \mu \mathrm{S}$ (corresponding to acidity $<0.8 \%$.) Similarly, all samples featuring $\mathrm{G}_{\mathrm{m}}>3.25 \mu \mathrm{S}$ are characterized by acidity $>0.8 \%$, while in the conductance range $2.75-3.25 \mu \mathrm{S}$ the samples acidity is close to $0.8 \%(0.68 \%$ to $0.85 \%)$.

In Fig. 4 (b), showing the results obtained with the full set of tested oils, each sample is represented by a dot as a function of acidity and peroxide index (determined by the standard procedures). All samples inside the dashed area are extra-virgin olive oils (acidity $<0.8 \%$ and peroxide index $<20$ ). As already mentioned, samples with high acidity feature high values of $G_{m}$. However, also samples with low acidity but high peroxide index exhibit high values of $\mathrm{G}_{\mathrm{m}}$.

The correlation between measured $\mathrm{G}_{\mathrm{m}}$, oil acidity and peroxide index has been tested using a Pearson correlation test with a significance of 0.05 . In both cases (the observed value is 0.752 for acidity and 0.599 for peroxide index with a bilateral p-value always lower than 0.0001 ) the test confirmed the presence of correlation.

A multiple linear regression analysis has been carried out to express $\mathrm{G}_{\mathrm{m}}$ as function of both acidity and peroxide index. The resulted equation is $G_{m}=2.11$ acidity +0.0478 peroxide +0.663 with a determination factor $\mathrm{R}^{2}=0.825$.

Clustering the samples according to measured $\mathrm{G}_{\mathrm{m}}$, all extra virgin olive oil samples are correctly distinguished from those of lower quality, except in one case where an oil is classified as extravirgin in spite of its peroxide index $>20$.

\section{A low-cost mobile sensor}

The measurements carried out using bench-top instrumentation described so far have indicated that the proposed technique can be reliably used to estimate the acidity (as well as quality loss due to oxidation) for olive oil samples. 
To this purpose, an embedded portable electronic system, in practice a complete sensor, has been realized that allows data to be collected directly at the olive oil mills, thus eliminating the need to ship samples to (often distant) laboratories for analysis, with significant advantages in terms of both time and costs.

The system is shown in Fig. 5 (a) and its schematic is illustrated in Fig. 5 (b). The "measurement head" is the same as that used with bench-top instrumentations, i.e. a 50ml tube with a couple of cap-shaped stainless steel electrodes. The electrical parameters of the SUT are measured by means of an electronic board designed ad-hoc and the data are transferred to a portable PC for visualization and backup.

Differently from the experiments with laboratory set-up, where the emulsion conductance $G_{m}$ has been measured over the whole impedance spectrum from $20 \mathrm{~Hz}$ to $2 \mathrm{MHz}$, the portable system operates at a single frequency $(200 \mathrm{~Hz})$ and estimates $\mathrm{G}_{\mathrm{m}}$ with $\operatorname{Re}(\mathrm{Y})$ as explained in Section 2.3. Since the measured conductance is small (few uS) the input sine-wave used in the portable system features an amplitude of $1 \mathrm{~V}$ (ten times larger than the one used with the laboratory set-up) to achieve higher signal-to-noise ratio. To this purpose, it has been verified that the increased amplitude of the test signal does not produce a significant difference in the measured conductance.

The schematic of the electronic board used to measure the emulsion conductance $G_{m}$ is presented in Fig. 5 (c). The sine-wave test signal is generated with an AD9833 function generator (600mV amplitude, $345 \mathrm{mV}$ DC offset and $200 \mathrm{~Hz}$ frequency). The generated signal $\left(\mathrm{V}_{\mathrm{a}}\right)$ is fed to a differential amplifier to remove the DC offset $\left(\mathrm{V}_{\mathrm{b}}\right)$ and for further amplification $\left(\mathrm{V}_{\text {in }}\right)$ to obtain a $200 \mathrm{~Hz}, 2 \mathrm{~V}_{\mathrm{PP}}$ sine-wave signal. The test signal $\mathrm{V}_{\text {in }}(\mathrm{t})$ is applied to the sensor electrodes only during the measurement (by means of two OMRONG6J-2FS-Y relais) and the current $\mathrm{I}_{\text {in }}(\mathrm{t})$ is measured with a current to voltage $(I / V)$ converter whose output $V_{\text {out }}(t)$ is linearly related to $I_{\text {in }}(t)$ :

$$
\frac{\tilde{V}_{\text {out }}}{\tilde{V}_{\text {in }}}=-\frac{R_{F}}{Z_{\text {sensor }}}=-R_{F} Y_{\text {sensor }}
$$


where $\tilde{V}_{\text {out }}$ and $\tilde{V}_{\text {in }}$ are Steinmetz transforms of the time domain signals $V_{\text {out }}(t)$ and $V_{\text {in }}(t)$. The feedback resistance $\mathrm{R}_{\mathrm{F}}$ is a programmable resistance $(0-100 \mathrm{kOhm}, 255$ steps $)$ whose value is set at the beginning of the measurements: the device has been initially calibrated and a look-at table has been set-up to associate the device digital input with the corresponding resistance value.

The signals $\mathrm{V}_{\text {in }}(\mathrm{t})$ and $\mathrm{V}_{\text {out }}(\mathrm{t})$ are then amplified and fed to 12-bits analog to digital converters (ADCs) providing a digital signal successively processed by the DSPIC33ep512 microcontroller (filtering out line and high frequency noise). The amplification gains of the $V_{c}$ and $V_{d}$ branches have been experimentally measured during board testing and the differences with the nominal values have been compensated via software.

Indicating with $\mathrm{V}_{\mathrm{dM}}$ and $\mathrm{V}_{\mathrm{cM}}$ the amplitude of the sinusoidal signals $\mathrm{V}_{\mathrm{d}}(\mathrm{t})$ and $\mathrm{V}_{\mathrm{c}}(\mathrm{t})$, respectively and with $\varphi$ the phase difference it is:

$\frac{\tilde{V}_{d}}{\widetilde{V}_{c}}=\frac{V_{d M} e^{j \varphi}}{V_{c M}}=\frac{\tilde{V}_{\text {out }}}{\tilde{V}_{\text {in }}}$

Thus from Eq (1), (3) and (4):

$\frac{V_{d M}}{V_{c M}} \cos (\varphi)+j \frac{V_{d M}}{V_{c M}} \operatorname{sen}(\varphi)=-R_{F} Y_{\text {sensor }}=-R_{F}\left(G_{m}+j \omega C_{m}\right)$

and the emulsion conductance $\mathrm{G}_{\mathrm{m}}$ can be estimated as:

$G_{m}=-\frac{1}{R_{F}} \frac{V_{d M}}{V_{c M}} \cos (\varphi)$

The parameters $\mathrm{V}_{\mathrm{cM}}, \mathrm{V}_{\mathrm{dM}}$ and $\varphi$ are estimated using the algorithm discussed in [22] based on the minimization of least square errors.

A user-friendly interface for the system has been created using the software LabVIEW (National Instruments, USA). The main panel of such an interface is shown in Fig. 6 (a). At the beginning of the measurement the user fills the sensor with $15 \mathrm{ml}$ of the hydro-alcoholic solution and performs a test (solvent test) to check whether or not the solution electrical properties are adequate, i.e. it is not too conductive. Then, $1 \mathrm{ml}$ of the olive oil to be tested is added and all is stirred to create the emulsion, whose $\mathrm{G}_{\mathrm{m}}$ is then measured to estimate the oil acidity. 
The measured value is represented on a slide graph providing immediate information about the oil quality ranking (extra-virgin olive oil, virgin olive oil or lampante olive oil).

A limited number of olive oil samples have been tested using the embedded system described above and the results are shown in Fig. 6 (b). As can be seen, the measured electrical conductance is correlated with oil acidity. Low acidity extra-virgin olive oils (featuring acidity $<0.4 \%$ ) all feature $\mathrm{G}_{\mathrm{m}}$ values lower than $2.75 \mu \mathrm{S}$, samples with acidity close to $0.8 \%$ are characterized by $\mathrm{G}_{\mathrm{m}}$ value between 2.75 and $3.25 \mu \mathrm{S}$, while virgin and lampante oil samples exhibit much larger conductance. The calculated linear regression line is $G_{m}=3.34$-acidity +0.95 and the determination coefficient $\mathrm{R}^{2}=0.98$

Future implementations of our portable system will feature a wireless communication system to allow rapid collection (and storing) of data for real-time, quick quality control.

\section{Conclusions}

A novel technique to measure acidity as a principal quality parameter of olive oil has been presented. The method is based on Electrical Impedance Spectroscopy, namely measurements of the electrical characteristics of an emulsion between the oil and a suitable hydro-alcoholic solution.

The results obtained with a significant lot of oil samples of different origin show that the electrical conductance $\mathrm{G}_{\mathrm{m}}$ of the emulsion can be used as a parameter to determine oil acidity. Furthermore, for samples with comparable values of acidity, $G_{m}$ increases because of stressing storage conditions (resulting in higher peroxide index).

In practice, then, the measured values of $G_{m}$ can be used to discriminate extra virgin olive oils (acidity $<0.8 \%$, peroxide index $<20$ ) from product of lower quality.

The technique has been implemented in the form of a low-cost portable electronic system suitable for rapid, in-situ quality checks even in small mills, as well as for distributed and on-line quality control by larger producers. 


\section{Acknowledgment}

This work has been financially supported by the CESAR Project, RIDIIT program, funded by the Ministry of Economic Development (Italy).

\section{References}

[1] S. Tulipani, M. Martinez Huelamo, M. Rotches Ribalta, R. Estruch, E. Escribano Ferrer, C. Andres-Lacueva, M. Illan, R.M. Lamuela-Raventós, Oil matrix effects on plasma exposure and urinary excretion of phenolic compounds from tomato sauces: Evidence from a human pilot study, Food Chem., 130 (2012) 581-590.

[2] F. Carbonari, T. Sarnari, Il mercato internazionale e nazionale dell'olio di oliva, ISMEA, 2013, pp. 1-13.

[3] R. Sacchi, L. Mannina, P. Fiordiponti, P. Barone, L. Paolillo, M. Patumi, Characterization of italian extra virgin olive oils using ${ }^{1}$ H-NMR spectroscopy, J. Agr. Food Chem., 4610 (1998) 39473951.

[4] EC 1991 Commission Regulation (EEC) $2568 / 91$ of July $11^{\text {th }} 1991$ on characteristics of olive oil and on the relevant methods of analysis. Official EC Journal, L248 (1991) 0001-0083.

[5] S. Armenta, S. Garrigues, M. de la Guardia, Determination of edible oil parameters by near infrared spectrometry, Anal. Chim. Acta, 596 (2007) 330-337.

[6] D. Ozdemir, B. Ozturk, Near infrared spectroscopic determination of olive oil adulteration with sunflower and corn oil, J. Food Drug Anal., 151 (2007) 40-47.

[7] A. G. Mignani, P. R. Smith, L. Ciaccheri, A. Cimato, G. Sani, Spectral nephelometry for making extravirgin olive oil fingerprints, Sensor Actuat. B-Chem., 90 (2003) 157-162.

[8] A. Cataldo, E. Piuzzi, G. Cannazza, E. De Benedetto, Dielectric spectroscopy of liquids through a combined approach: evaluation of the metrological performance and feasibility study on vegetable oils, IEEE Sensor J., 910 (2009) 1226-1233. 
[9] A. Cataldo, E. Piuzzi, G. Cannazza, E. De Benedetto, L. Tarricone, Quality and anti-adulteration control of vegetable oils through microwave dielectric spectroscopy, Measurement, 43 (2010) 10311039.

[10] Ya.I. Tur'yan, O.Yu. Berezin, I. Kuselman, A. Shenhar, pH-metric determination of acid values in vegetable oils without titration, J. Am. Oil Chem. Soc., 733 (1996) 295-301.

[11] B.-Y. Chang, S.-M. Park, Electrochemical impedance spectroscopy, Annu. Rev. Anal. Chem., 3 (2010) 207-229.

[12] M. Chanet, C. Riviere, P. Eynard, Electric impedance spectrometry for the control of manufacturing process of comminuted meat products, J. Food Eng., 42 (1999) 153-159.

[13] R. Zywica, G. Pierzynowska-Korniak, J. Wojcik, Application of food products electrical model parameters for evaluation of apple puree dilution, J. Food Eng., 67 (2005) 413-418.

[14] F.R. Harker, J.H. Maindonald, Ripening of nectarine fruit: changes in the cell wall, vacuole and membranes detected using electrical impedance measurement, Plant Physiol., 106 (1994) 165171.

[15] F.R. Harker, S.H. Forbes, Ripening and development of chilling injury in persimmon fruit: an electrical impedance study, New Zeal. J. Crop Hort., 25 (1997) 149-157.

[16] M. Grossi, M. Lanzoni, A. Pompei, R. Lazzarini, D. Matteuzzi, B. Riccò, Detection of microbial concentration in ice-cream using the impedance technique, Biosens. Bioelectron., 23 (2008) 1616-1623.

[17] M. Grossi, A. Pompei, M. Lanzoni, R. Lazzarini, D. Matteuzzi, B. Riccò, Total bacterial count in soft-frozen dairy products by impedance biosensor system, IEEE Sensor J., 910 (2009) 12701276.

[18] M. Grossi, M. Lanzoni, A. Pompei, R. Lazzarini, D. Matteuzzi, B. Riccò, A portable biosensor system for bacterial concentration measurements in cow's raw milk, P. $4^{\text {th }}$ IEEE Int. Wksp. Adv. Sensor Interfac. (IWASI), Savelletri di Fasano, Italy, (2011) 132-137. 
[19] A. Pompei, M. Grossi, M. Lanzoni, G. Perretti, R. Lazzarini, B. Riccò, D. Matteuzzi, Feasibility of lactobacilli concentration detection in beer by automated impedance technique, MBAA Tec. Q., 491 (2012) 11-18.

[20] M. Grossi, R. Lazzarini, M. Lanzoni, A. Pompei, D. Matteuzzi, B. Riccò, A portable sensor with disposable electrodes for water bacterial quality assessment, IEEE Sensor J., 135 (2013) 17751782.

[21] E. Boselli, G. Di Lecce, M. Minardi, D. Pacetti, N.G. Frega, La spettrometria di massa nell'analisi di componenti minori polari dell'olio vergine di oliva, Riv. Ital. Sostanze Gr., 84 (2008) 3-14.

[22] M. Grossi, M. Lanzoni, R. Lazzarini, B. Riccò, Linear non iterative sinusoidal fitting algorithm for microbial impedance biosensor, Sensor Transducer J., 1372 (2012) 235-244. 


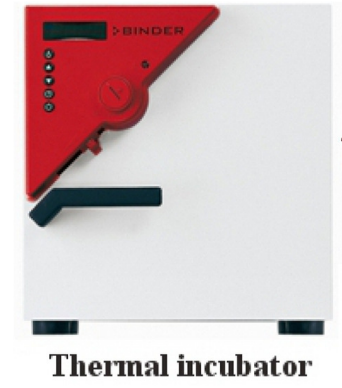

(a)

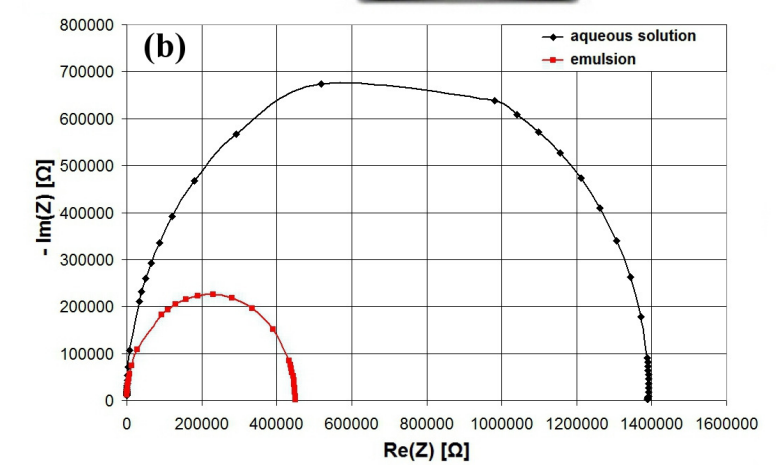

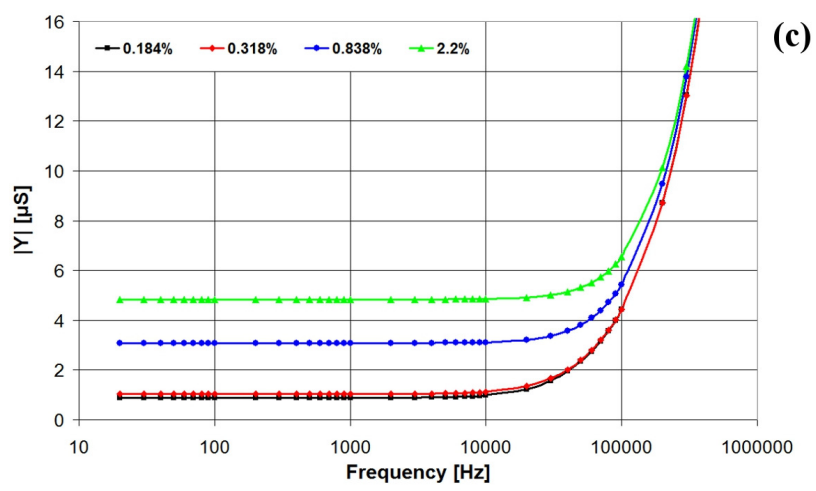

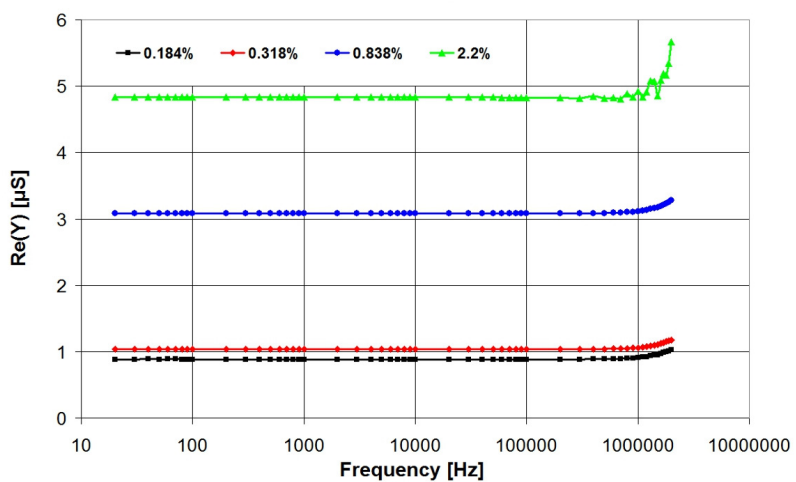

Fig. 1 The experimental set-up used to develop, optimize and validate the technique of this work (a). The Nyquist plot for both the hydro-alcoholic solution and the emulsion (b). $|\mathrm{Y}|$ and $\operatorname{Re}(\mathrm{Y})$ plotted vs. frequency for emulsions with oils featuring different values of acidity (c). 

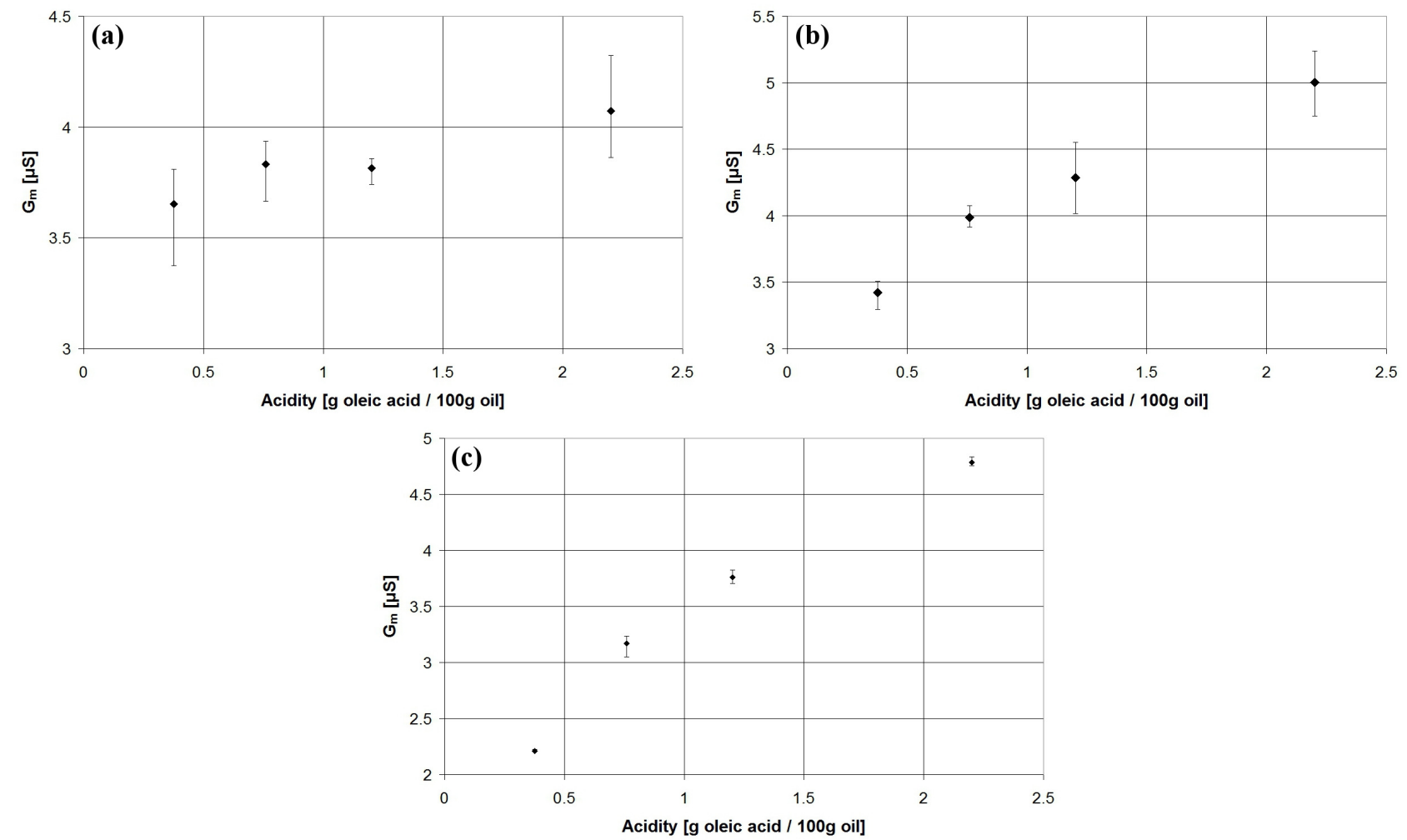

Fig. 2 Emulsion conductance $G_{m}$ vs. oil acidity in case of emulsion realized with: $15 \mathrm{ml}$ of oil and $15 \mathrm{ml}$ of hydro-alcoholic solution (a); $5 \mathrm{ml}$ of oil and $15 \mathrm{ml}$ of hydro-alcoholic solution (b); $1 \mathrm{ml}$ of oil and $15 \mathrm{ml}$ of hydro-alcoholic solution (c). 


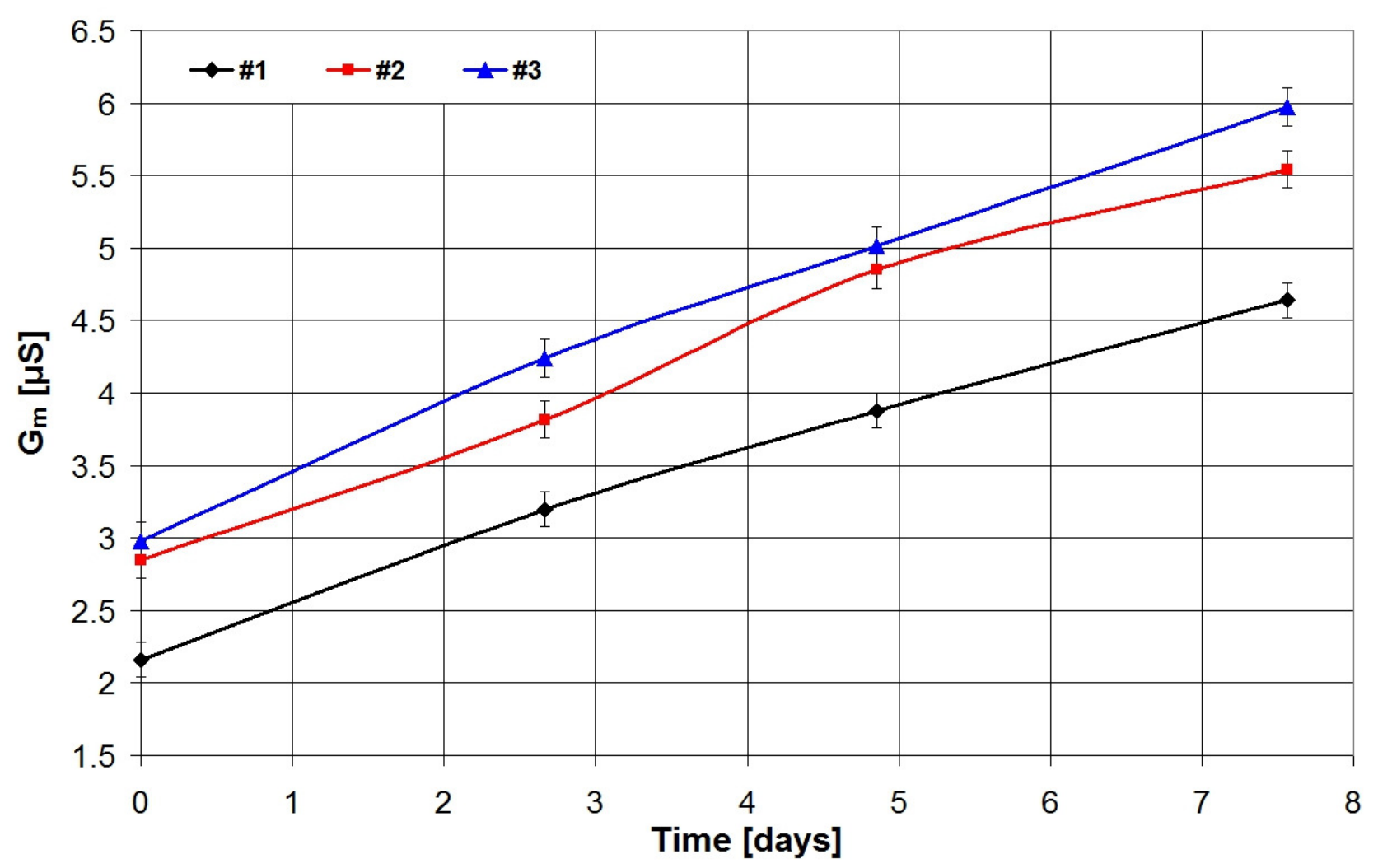

Fig. 3 Emulsion conductance $G_{m}$ vs. UV exposure time for three different extra-virgin olive oil samples. 

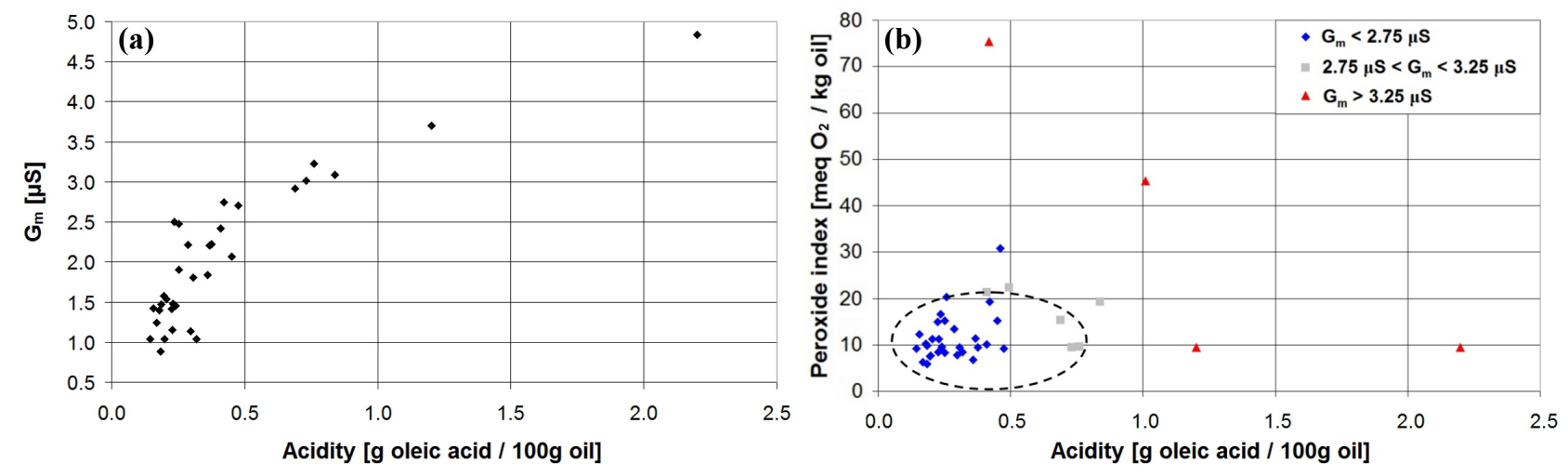

Fig. 4 Emulsion conductance $G_{m}$ vs. oil acidity for a subset of olive oils featuring peroxide index < 20 (a). A scatter plot of the full set of tested oils plotted as a function of acidity and peroxide index. The samples inside the dashed area are extra-virgin olive oils (b). 

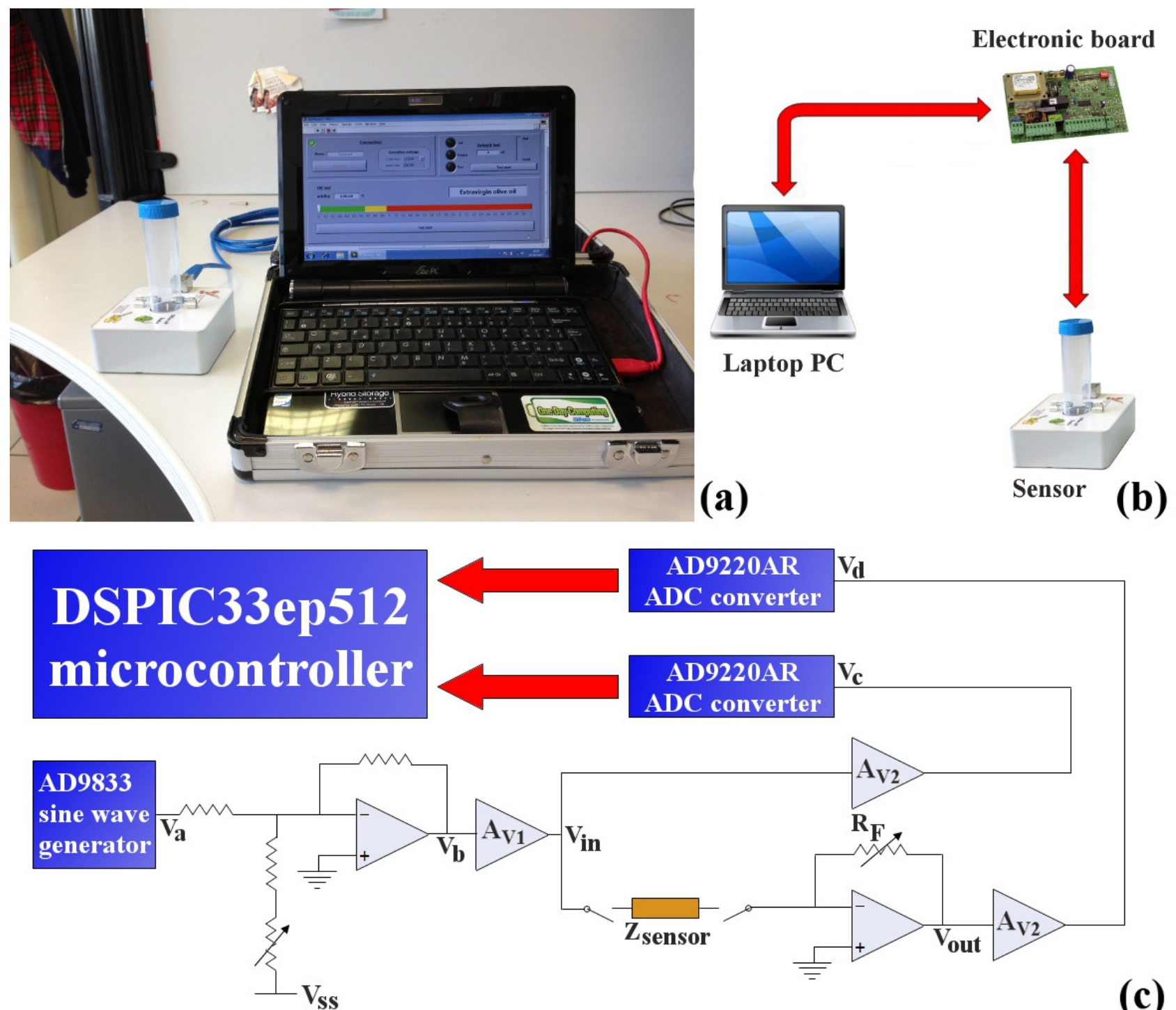

(c)

Fig. 5 Picture (a) and schematic (b) of the portable embedded system for olive oil acidity determination. Electrical schematic (c) of the system electronic board. 

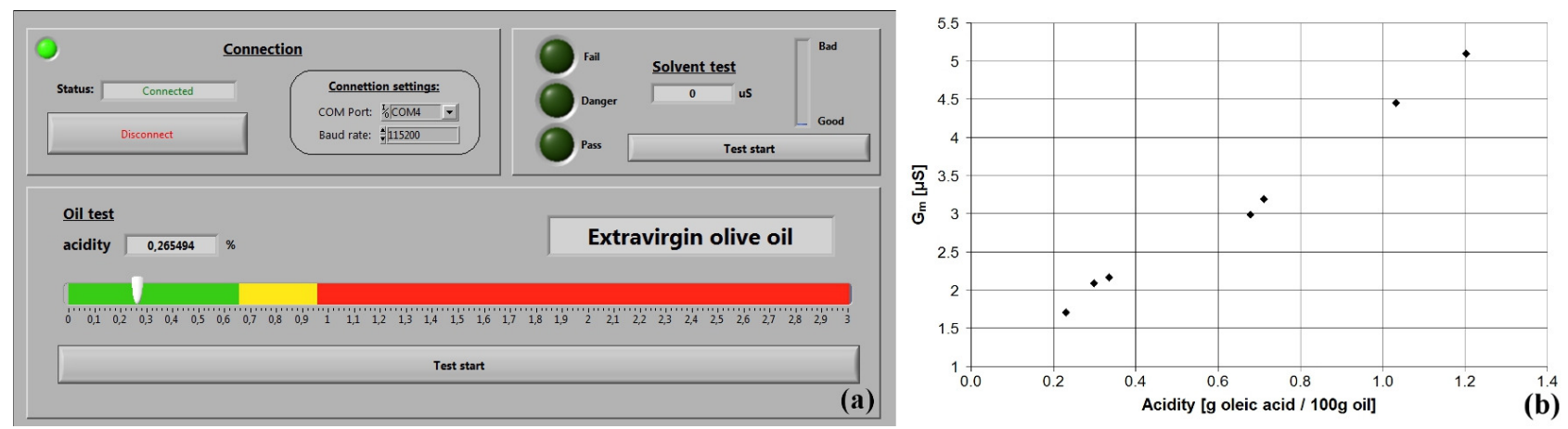

Fig. 6 Front panel of the software used to control the embedded system (a). Electrical conductance measured with the embedded system plotted vs. oil acidity for different olive oil samples (b). 


\begin{tabular}{|c|c|c|c|}
\hline \multirow{2}{*}{ Oil to aqueous solution ratio } & \multicolumn{3}{|c|}{ Sensor performance } \\
\cline { 2 - 4 } & Sensitivity $(\boldsymbol{\mu S} / \%)$ & Error in acidity estimation (\%) & Non linearity (\%) \\
\hline $15 \mathrm{ml}: 15 \mathrm{ml}$ & 0.21 & 1.528 & 16.26 \\
\hline $5 \mathrm{ml}: 15 \mathrm{ml}$ & 0.82 & 0.424 & 7.98 \\
\hline $1 \mathrm{ml}: 15 \mathrm{ml}$ & 1.34 & 0.0756 & 9.87 \\
\hline
\end{tabular}

Table 1 Sensor performance as function of the oil / aqueous solution ratio. 